\title{
ENSINO DO DESIGN EM CONTEXTOS REAIS PARA A PRESERVAÇÃO DA IDENTIDADE E MEMÓRIA LOCAL
}

\section{TEACHING DESIGN IN REAL CONTEXTS TO PRESERVE LOCAL IDENTITY AND MEMORY}
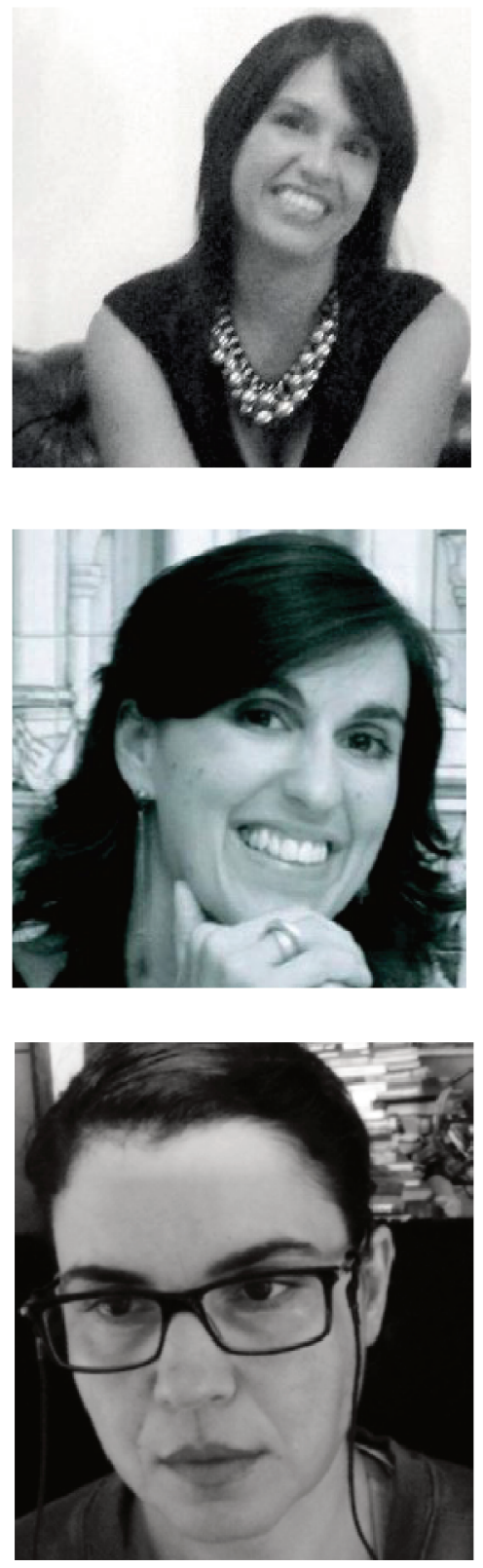

\section{Cátia Rijo}

Doutora - Faculdade de Arquitetura de Lisboa

Mestre em Produção gráfica IADE (Instituto de Artes

Visuais, Design e Marketing).

Licenciada em Design Visual pelo IADE

catia.rijo@gmail.com

\section{Helena Gracio}

Doutora - design na Faculdade de Arquitetura da Universidade de Lisboa

licenciada pela Universidade Lusíada de Lisboa.

professora Adjunta na Escola Superior de

Educação, Politécnico de Lisboa

ahgracio@gmail.com

\section{Sandra Antunes}

Pós-graduada em Design de Produto pelo Instituto de Arte, Design e Empresa - Universitário de

Lisboa (IADE-U)

Doutoranda em Design/História da Cultura Material

e Imaterial pela IADE-U

antunes.sandra.design@gmail.com 


\section{RESUMO}

O presente artigo apresenta um projeto colaborativo caracterizado pelo diálogo interdisciplinar em contextos de educação formal, informal e culturalmente plurais, considerando práticas educativas alternativas ao modelo de sala de aula. O caso exposto ocorreu na vila portuguesa de Nisa.

Reunindo artesãos, designers e artistas, ao par de estudantes da Licenciatura em Artes Visuais e Tecnologias (da ESELx do Instituto Politécnico de Lisboa); integrando os estudantes no contexto; providenciando-Ihes experiência da cultura e memória locais - aspirámos alcançar formas de projetar no futuro a memória e a herança material e imaterial guardadas na diversidade humana e material; refletindo simultaneamente sobre metodologias colaborativas e participativas no ensino e pesquisa em design.

\section{PALAVRAS-CHAVE:}

Ensino do Design. Plataformas Colaborativas. Contextos Educativos

\section{ABSTRACT}

This paper presents a collaborative project defined by interdisciplinary dialogue in formal, informal and culturally plural learning contexts, considering educational practices alternative to the classroom model. The present case takes place in the Portuguese village of Nisa. Gathering artisans, designers and artists, along with students from the Visual Arts and Technologies Degree (from Lisbon's Polytechnic ESELx); merging students in context; providing them experience of local culture and memory - we aim to achieve ways of projecting in the future material and immaterial memory and heritage kept within human and material diversity; reflecting also on collaborative and participative methodologies in design teaching and research.

\section{KEYWORDS :}

Design Teaching. Collaborative Platforms. Educational Contexts.

\section{Introdução}

A experiência de ensino em Design que ora apresentamos é caracterizada pela multidisciplinaridade dos seus atores; o enfoque na investigação/ação; a imersão de docentes e estudantes em contextos locais reais e a consideração na atividade projetual de toda a dimensão humana e cultural do contexto de ensino/aprendizagem de imersão. Esta experiência foi colaborativamente orga- 
nizada pelas autoras enquanto docentes da Unidade Curricular de Projecto II, área projetual que compreende os ramos de Design de Produto e de Design de Interação, havendo sido implementada junto dos estudantes do segundo ano do Curso de Licenciatura em Artes Visuais e Tecnologias, da Escola Superior de Educação do Instituto Politécnico de Lisboa (Portugal) naquela que foi, note-se, a primeira aproximação ao Design de Produto por parte dos citados alunos. Os trabalhos e as imagens que visualmente documentam este nosso artigo resultam da citada experiência.

A questão de investigação inicialmente colocada pelas autoras prende-se com a procura de alternativas projetuais aos modelos de ensino não participativos/ colaborativos, tradicionalmente focados na sala de aula.

Assim, assumiu-se igualmente como objetivo da nossa investigação compreender que mais--valias para o projeto decorrem da identidade do nosso grupo de trabalho, constituído por agentes: das artes plásticas, do design gráfico, do design de produto e do design de interação. Crucial para o desenvolvimento do projeto manifestou-se a imersão dos estudantes nas comunidades locais: com as suas gentes, a sua cultura, a particularidade do seu saber técnico e empírico, a sua identidade, a sua memória, mas igualmente o sentido das suas aspirações futuras. Caracterizando a nossa ação sublinhamos: a nossa interdisciplinaridade, a importância dada à prática e à experimentação como formas de pesquisa/ conhecimento; a observação e a consideração da cultura material e imaterial locais; o conhecimento seu inerente, as suas técnicas, matérias primas e as tecnologias locais ainda preservadas nas atividades produtivas.

Sob tal enquadramento, juntando estudantes, agentes das várias áreas citadas e integrado--os junto dos artesãos de olaria em pedrada de Nisa, Alto Alentejo (Portugal) - grupo de quem, nos nossos dias, apenas três representantes existem - e da comunidade humana residente no local:

- Foi nosso propósito implementar, observar e refletir acerca da aplicação de metodologias colaborativas e participativas no ensino e pesquisa em design. Ao fazê-lo foi ainda nosso intuito quer contribuir para a pesquisa e desenvolvimento criativo de aproximações projetuais prospetivas para o ensino e a pesquisa em design; quer induzir o descentrar o estudante de si próprio, refoçando-o no utilizador, nos contextos produtivos e também nos seus efeitos. Convidando pois ao estudo e à reabilitação de matérias primas com características peculiares; à criação, mais que de objetos, de serviços e de experiências capazes de revitalizar a comunidade humana nativa e de transmitir a herança e as memórias locais: projetando igualmente os efeitos dos produtos, serviços e 
experiências concebidos.

Uma aspiração que somente foi possível e alcançar através do envolvimento dos estudantes em cenários de contexto real, induzindo-os a projetar não para, mas com as comunidades locais.

Num mundo em que a comunicação impera, o envolvimento do Design de Interação no processo protagonizou uma ligação entre as dimensões local e global. Desenhando interfaces de carácter local e global, os alunos consideraram as pessoas não como elementos funcionais, habilitando redes de comunicação com feedback formativo.

A par de plataformas colaborativas de natureza local, o projeto desenhou plataformas colaborativas de dimensão global. Neste processo a diversidade local (humana, material e imaterial) assumiu um papel significativo coligindo, por interação com terceiros, reconhecimento coletivo da singularidade e especificidade cultural. Em consonância com Hall ([1992] 2004), atestando que um dos aportes da globalização é o fortalecimento das identidades locais ou a criação de novas identidades, uma vez que a globalização encerra a cultura local a um nível global, transmitindo a outros aquela especificidade e factores distintivos, granjeando consequentemente o reconhecimento daquela por parte do coletivo.

Reunindo as experiências e os resultados obtidos por ação do projeto, é intuito da plataforma desenhada a disseminação das experiências e dos resultados obtidos junto de novos grupos de trabalho, e a recepção de feedback por parte daqueles, providenciando virtualmente o debate e a reflexão de dimensão local e global. O fenómeno globalização liga áreas distantes, mas pode simultaneamente desligar o passado e o presente. É tarefa do designer desempenhar um papel de mediador neste contexto, possibilitando a ligação entre esta e diferentes realidades. Parece-nos pois apropriado o estabelecer desta reflexão, facultando à herança cultural a aquisição de novos contornos. Compreendendo o design como uma atividade integrada nos contextos nos quais ele opera e dialoga, defendemos que apenas através do conhecimento transversal da realidade histórica e sócio-cultural podem alcançar-se resultados verdadeiramente consequentes e sustentáveis no que aos seus efeitos diz respeito.

Desenvolvida desta forma, a interação do designer com os problemas factuais, as comunidades no ativo e as suas práticas conduzem ao design de estratégias, ferramentas e ambientes capazes de nutrir o desenvolvimento de pesquisa coadjuvada pelas diversas áreas envolvidas. Fundados e conduzidos pela prática, métodos oportunos foram criados e testados através do fazer e da interação. 


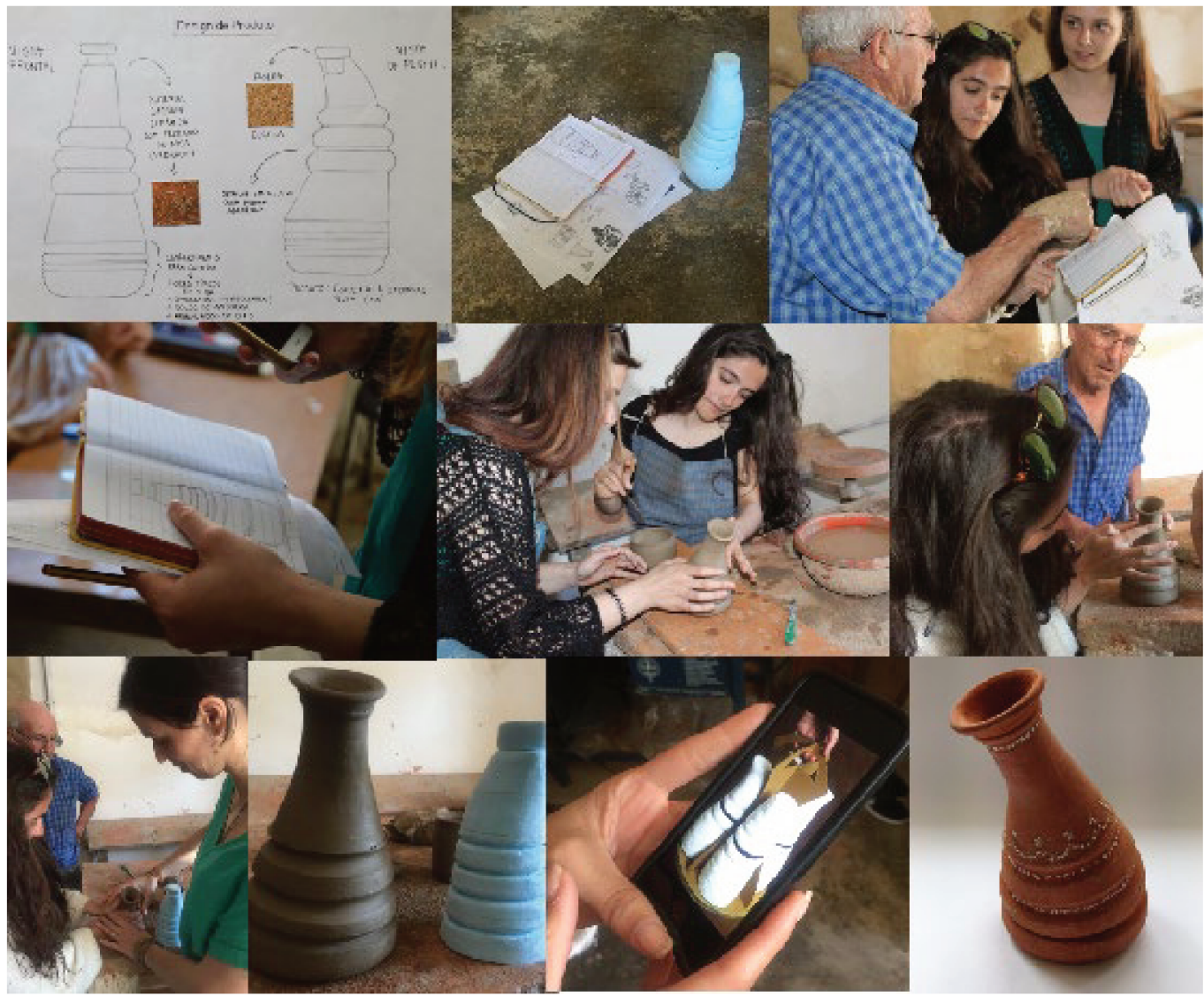

Figura 1 - Evolução do projeto "Um Pouco Mais ou Menos" das alunas Romana Soares e Yuliya Golodynska, que retrata a evolução do projeto desde o esboço ao protótipo. Fotos das autoras.

\section{Design da Investigação}

"Na paisagem transdisciplinar, quando confrontamos um problema, quando descobrimos uma contradição, os planos (as receitas usuais) resultam insuficientes; não basta a visão local que caracteriza o pensamento simples (Morin) ou de localização simples (Arnold Whitehead). Este pensamento não é mais que um ponto de partida [...] insuficiente para descobrir os caminhos e descrever os vínculos além do 
Com o intuito de atuar em terreno transdisciplinar, planificando no sentido de permitir aos estudantes algum tempo para a exploração/experimentação de sistemas por vias não lineares (com tempo para a discussão e reformulação de propostas ao longo da fase de anteprojeto) reservámos a duração de um semestre para o desenvolvimento do presente projeto.

Reunindo artesãos aos nossos agentes, foi nossa intenção fomentar o diálogo interdisciplinar entre contextos de aprendizagem de características formais, informais, cultural e geracionalmente plurais.

Procurar práticas educacionais e projetuais alternativas ao modelo não participativo centrado no indivíduo na sala de aula, na comunicação unívoca e na especialização de saberes - experiência imersiva/investigação aplicada - foi igualmente factor crucial no desenho da nossa investigação, permitindo um descentrar da experiência conhecida do próprio, das suas expectativas e pré-conceitos, proporcionando maior permeabilidade à incorporação de elementos (quer de índole material, quer imaterial) do ambiente de imersão. Por esta via, diligenciámos ainda no sentido do aprimoramento da capacidade de vislumbrar possíveis realidades futuras, uma vez que o trabalho do designer é prospectivo.

A integração da prática como instrumento de pesquisa caracterizou igualmente o desenho da nossa ação - practice-based e practice-led (Candy, 2006) - considerando: quer a prática e a reflexão acerca dos resultados da prática; quer o artefacto criado como uma fonte de novo conhecimento e de investigação; ou ainda uma procura capaz de levar a novo conhecimento ou a nova ação prática. Observando-se desta forma o conhecimento sobre a prática ou dentro dela. Uma questão que consideramos inerente à ação do designer, para quem, como agente em área de prática criativa, os resultados da pesquisa muitas vezes se manifestam como não linguísticos ou inefáveis - abrindo muitas vezes portas à descoberta de "algo" que não poderia ter-se descoberto por outros meios (Büchler \& Biggs, 2008).

1 «En el paisaje transdisciplinario, cuando confrontamos un problema, quando descubrimos una contradicción, los programas (las recetas consabidas) resultan insuficientes; no basta la vision local que caracteriza al pensamiento simple (Morin) o de localizacioón simple (Arnold Whitehead). Este pensamiento no es más que punto de partida [...] insuficiente para descubrir los caminos y describir los vínculos más allá de lo local.» (Juez,2002, p.124-130). 


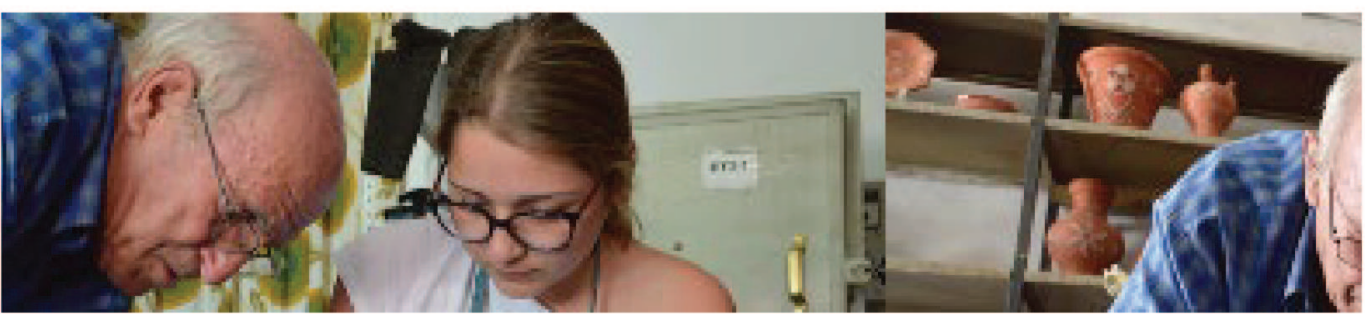

Figura 2 - Os alunos com o artesão Mestre Pequito em trabalho colaborativo.

\section{Metodologia}

De mente aberta, procurando não induzir os nossos agentes a pensar a partir de modelos fixos - não adaptativos por inerência - iniciámos o nosso projeto com uma primeira deslocação à Vila de Nisa, uma visita cultural, ainda sem que um briefing houvesse sido dado aos estudantes.
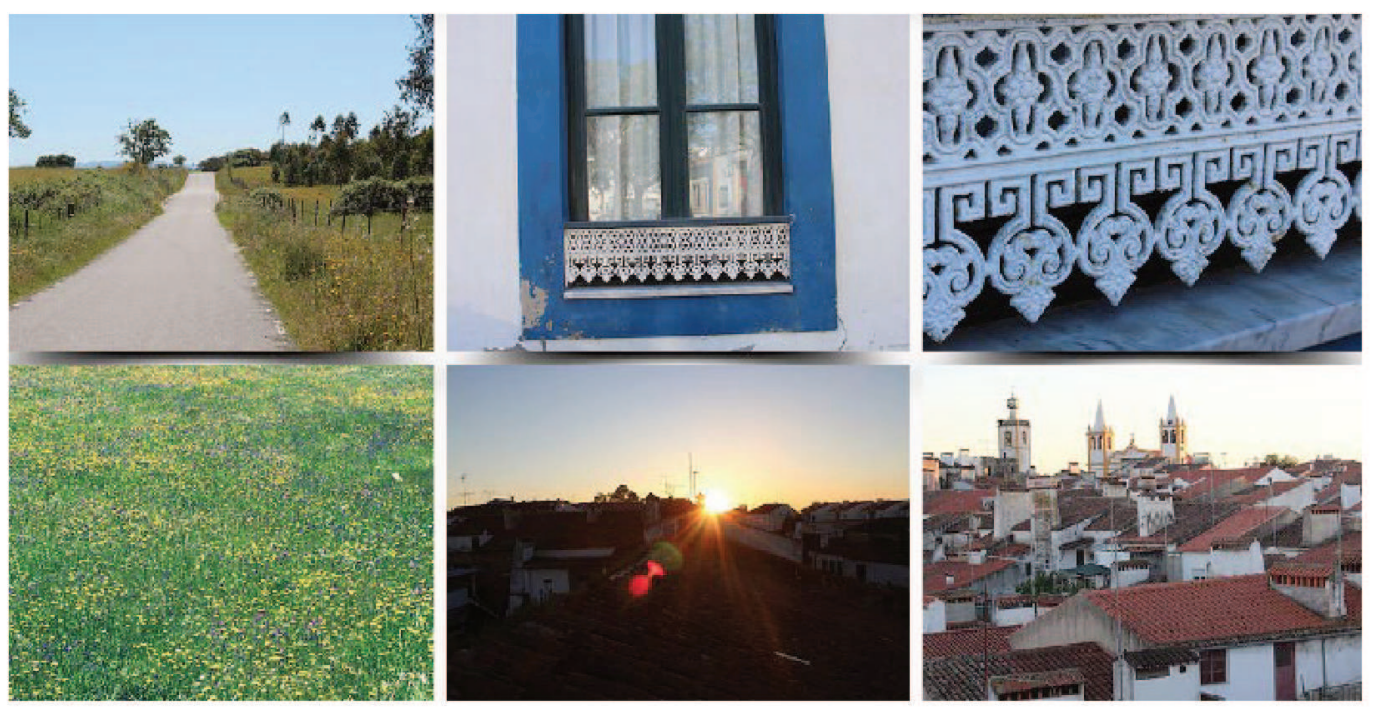

Figura 3 - A aldeia de Nisa pelo olhar dos alunos. Fotos dos alunos.

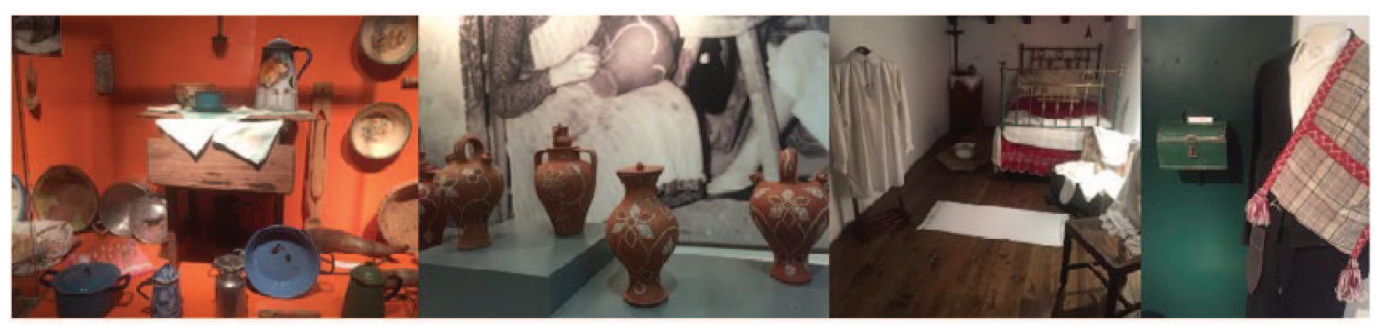

Figura 4 - Visita ao Museu do Bordado e do Barro, Nisa. Fotos dos alunos. 


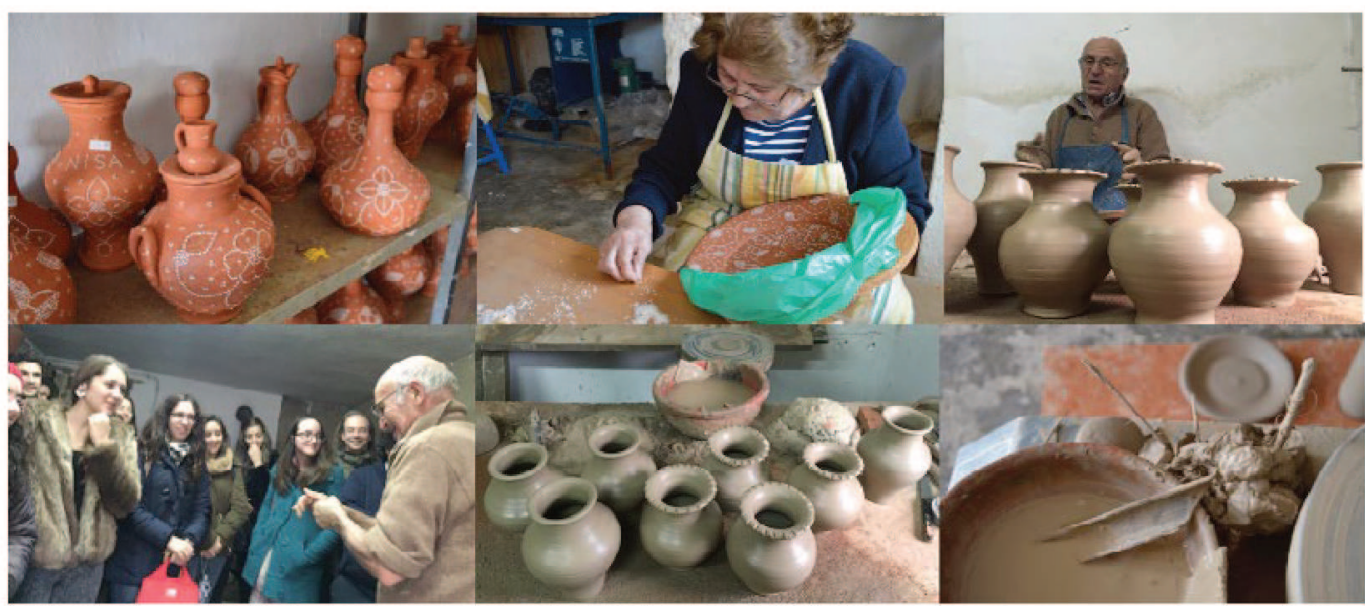

Figura 5 - Visita à olaria do Mestre Pequito. Foto dos alunos.

De volta ao Politécnico, no contexto das unidades curriculares de Design de Produto e de Design de Interação, foi proposto aos estudantes o desafio da "revitalização e transmissão da herança e da cultura da comunidade com a qual haviam tido algum entrosamento, por via do desenho de processos colaborativos entre o design e o artesanato ou a cultura locais. Tendo presente que a identidade cultural desempenha um papel fulcral na identificação do indivíduo com o espaço, é nosso dever divulgar e preservar este legado para as gerações futuras, perpetuando a identidade da comunidade local, que sintetiza em si a sua história com um código que evoca a nossa personalidade (Rijo, 2014). $\mathrm{Na}$ unidade curricular de Design de Produto, assumindo o design como uma forma de pesquisa aplicada e o desenho como uma ferramenta de pesquisa multissensorial - o processo iniciou com a narração de memórias.

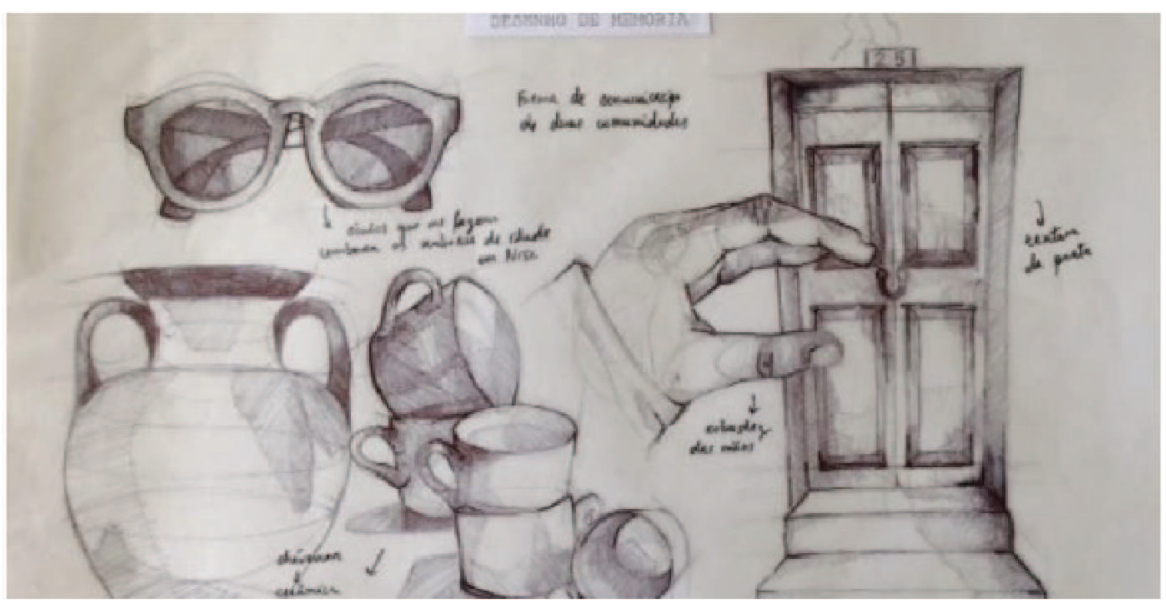

Figura 6 - Skeching para a narração de memórias, projeto Organ, de Susana Rodrigues 
e Tamára lomba. Foto das autoras

A este nível, a solicitação da comunicação de memórias não pretendeu o coligir de registos do passado, mas a reunião de index decorrentes da primeira experiência empírica dos estudantes naquele capo de imersão. De facto, deve ter-se em mente que uma parte significativa da produção corrente é baseada no passado, num conjunto de dados coligidos de histórias, de memórias e da experiência passadas de um dado grupo de foco/ou do chamado "homem médio". Um caminho que não corresponde de todo àquilo que aqui se pretendeu, aspirando alcançar-se a observação do que Fukuda (2015) designa de "satisfação das expectativas" par da consideração não somente do produto, do serviço ou da experiência, mas também dos seus efeitos.

"[...]«no futuro aquilo que deveremos projetar são os efeitos, não os produtos, nem os

serviços. Devemos superar as especializações, devemos superar o design tal como o temos vindo a conceber até agora». ${ }^{2}$

Este foi o objectivo que nos propusemos alcançar. Para tal adaptação, variabilidade e mudança (Juez, 2002,124) formam a cada momento requeridas.

Lutando contra contingências de tempo, a necessidade de cumprir um programa e a manutenção de registos de avaliação, lança-se um ponto de ancoragem: a solicitação da criação de uma lancheira (restringindo embora as opções ao uso de matérias primas locais). Deste ponto em diante a investigação prossegue. Percorrendo as diversas dimensões envolvidas, analisa-se e desenvolve-se o estado da arte; o estudo de materiais, de técnicas e de tecnologias. Não perdendo de vista adaptação, variabilidade e mudança, a luta é agora no sentido da desconstrução das ideias pré concebidas e apresentadas como finalizadas pelo estudante. Para a revitalização e transmissão da herança cultural, a construção de plataformas colaborativas e a análise e pesquisa no sentido da satisfação das expectativas futuras da comunidade, não foram ainda satisfeitas as exigências. Então um novo conjunto de estádios de trabalho é lançado, com investigação a ser comunicada por sketch: questões sobre ergonomia e fatores humanos e sobre o mercado e o público alvo.

2 “[...] «nel futuro ciò che dobbiamo progettare sono gli effetti, non i prodotti né i servizi. Dobbiamo superare le specializzazioni, dobbiamo superare il design come l'abbiamo concepito finora»." (Ferrara, 2016). 


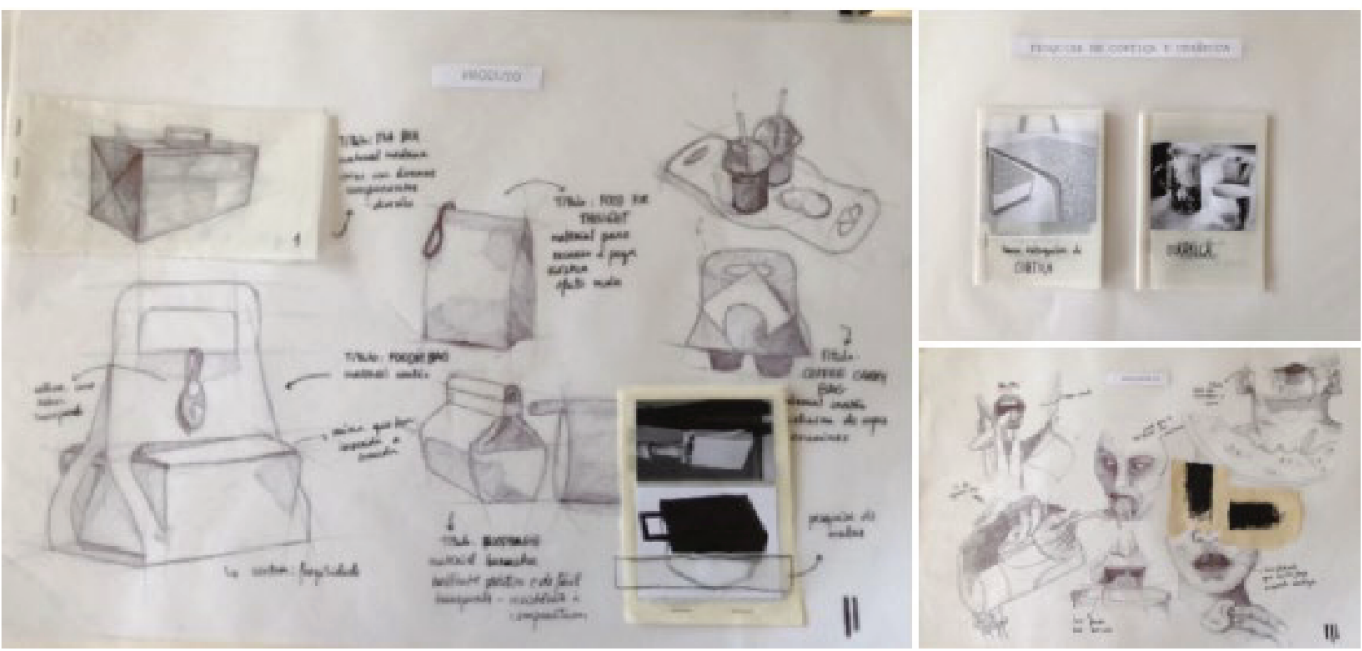

Fig.7 - Skechings para a exploração do produto e ergonomia, uso das matérias primas, funcionalidades, etc. Projeto Organ de Susana Rodrigues e Tamára lomba. Foto das autoras.

Por esta altura, com a diversidade de informação recolhida, o estudante está a ser conduzido até un estado completamente nuevo (Juez,2002,p.124), encontrando-se agora em condições de contrapropor um (de)brief com o objetivo de melhor responder ao desafio que inicialmente lhe foi lançado: - a revitalização e transmissão da herança e das memórias locais, construindo processos colaborativos entre o design as gentes e os ofícios locais.

Localizado agora num novo estádio conceptual, à sua própria contra-proposta, que recorrentemente tende a apresentar como finalizada, o estudante é agora persuadido a ousar ainda aplicar adaptação, variabilidade e mudança (Juez, 2002, p.124), desta feita através de metodologias do âmbito da Biologia, nomeadamente da Síntese Moderna da Evolução:

"O termo «síntese evolutiva» foi introduzido por Julian Huxley em Evolution: The Modern Synthesis (1942) para designar a aceitação geral de duas conclusões: a evolução gradual pode ser explicada em termos de pequenas mudanças («mutações») e recombinação, e a ordenação dessa variação 
genética por seleção natural [...]."(Mayr \& Provine, [1980] 1998,1). ${ }^{3}$

Assumido este caminho, o passo seguinte consistiu em investigar os contextos de produção do ponto de vista humano, natural, cultural, mecânico ou digital; seguido da investigação em questões de desmaterialização e sustentabilidade (natural, humana, económica e cultural) - todos estes estádios da investigação aplicada comunicados por sketch.

Sob a premissa da investigação aplicada e do design com a comunidade; munido o grupo de trabalho de toda a investigação coligida, interrogada e sintetizada até ao momento, este foi o momento da nova imersão em contexto real/ local. No estádio de desenvolvimento atual do projeto, um grupo voluntário de estudantes e professores da áreas acima mencionadas voltaram ao terreno, numa residência de três dias junto da comunidade local. Para o trabalho de campo socorremo-nos, entre outras, de ferramentas de pesquisa do âmbito das Ciências Sociais e Humanas, especialmente do plano da Antropologia e da Etnografia, possibilitando-nos estas a observação e o registo de diversas dinâmicas conjunturais (geracionais, ambientais, económicas, tecnológicas do contexto do bem estar material e imaterial, das redes locais e das suas relações sociais). Significando isto que muitos dados novos foram gerados através de observação direta dos agentes no terreno e interação com os respondentes, em múltiplas dimensões da sua existência, em contexto de imersão no local. Após esta última experiência por parte do grupo de agentes voluntários, a necessidade de trazer mudanças aos projetos anteriormente pensados foi notória. No final do processo observou-se que o caminho desenvolvido desde a lancheira até à contra-proposta dos estudantes e ao projeto proposto pelos voluntários na fase de imersão final em contexto local foi a mais diversificada, percebendo-se claramente as propostas submetidas pelos indivíduos que tomaram parte nas duas residências como as mais criativas e adequadas.

\section{Resultados}

O designer deve retratar as características diferenciadoras do espaço e comuni-

3 The term «evolutionary synthesis» was introduced by Julian Huxley in Evolution: The Modern Synthesis (1942) to designate the general acceptance of two conclusions: gradual evolution can be explained in terms of small changes («mutations») and recombination, and the ordering of this genetic variation by natural selection [...]."(Mayr \& Provine, [1980] 1998,1).

Um modelo que em Portugal é defendido pelo Doutor António Cruz Rodrigues nas suas aulas de Design Industrial. 
cá-las ao exterior,

"[...] para atingir este objetivo o designer deve avaliar as características diferenciadoras, a fim de obter uma representação da identidade do espaço ao mesmo tempo que desenvolve uma relação emocional com o receptor (...); é um profissional do projeto que contribui para que a diversidade do espaço seja percebida e compreendida pelo maior número de pessoas a fim de preservá-lo num nível intangível" (Rijo, 2014).

Apresentamos alguns dos resultados obtidos no final do processo de trabalho que temos vindo a descrever. Note-se como a possibilidade de uma investigação aplicada em design; integrada e integradora do diálogo interdisciplinar; assumindo como pertinentes alguns dos pontos de intercepção da visão e da ação de designers, artistas plásticos, artesãos e as comunidades, pode tornar-se frutífera, reforçando o interesse e a pertinência quer deste projeto quer das metodologias de trabalho por ele empreendidas. Observe-se o varrimento de campo empreendido e a diversidade das propostas apresentadas pelos estudantes: da gastronomia à música; da joalharia à didática - mas todos eles projetos de responsabilidade social.

\section{Projeto "Joias Iovis" dos alunos Rui Medronho e Rita Lopes}

«O projeto tem como objetivo a valorização do património português dando resposta às necessidades colocadas pelos artesãos de Nisa através da criação dum produto desafiante e inovador. O nosso projeto foca-se então na proteção do património de Nisa, nomeadamente na olaria pedrada, através de um produto inovador ao qual decidimos atribuir o título de Joalharia Pedrada. Como o título indica, o nosso projeto baseia-se na criação de peças com os materiais típicos da olaria pedrada - barro e quartzo - possibilitando deste modo que os artesãos de Nisa possam estender a sua gama de produtos. O nosso projeto parte de uma linha minimalista com temáticas relacionadas com Nisa, nomeadamente os vestígios romanos existentes na zona. Assim sendo decidimos chamar ao nosso projeto/marca IOVIS - variante latina do nome dado a Júpiter, deus então venerado na zona de Nisa. Para suportar o nosso projeto procedemos à criação de um website de divulgação e loja do produto.» 

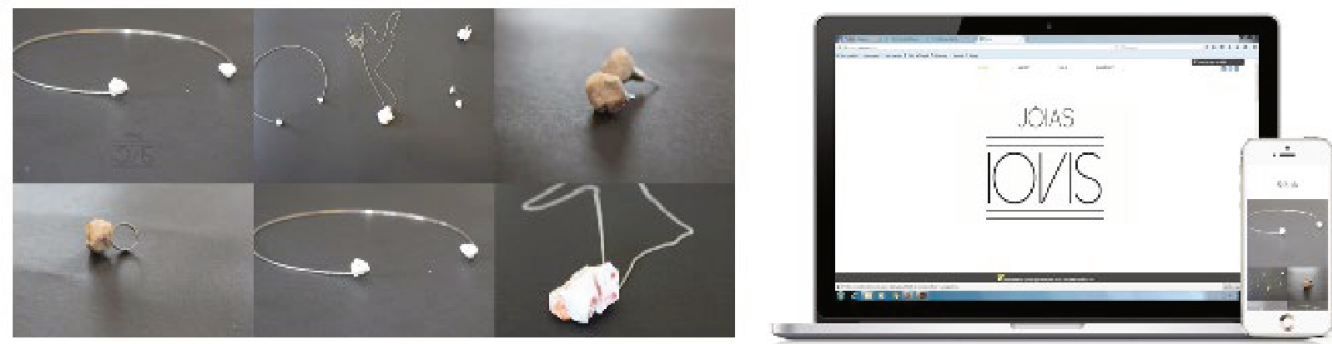

Figura 8 - Pormenores de "Joias lovis" e o respetivo mockup do site de divulgação. Foto dos autores.

\section{Projeto "Nisatool" dos alunos Bernardo Monteiro e Patrícia Roque} «O Nisatool consiste num cinto de ferramentas inspirado na Olaria Pedarada de Nisa. O seu objetivo passa por facilitar e inovar algumas das técnicas presentes neste ofício, tornando a atividade do artesão mais funcional. Pretende-se desta forma explorar e divulgar a tradição de Nisa, transportando o utilizador para uma experiência com décadas de existência. Em simultâneo o produto tem a intenção de comutar perspetivas culturais de diferentes públicos, desde o típico oleiro desta região até ao novo utilizador. As diferentes perceções permitem ao Nisatool proporcionar duas vertentes complementares aos seus utilizadores: por um lado o artesão vê as suas ferramentas serem aperfeiçoadas, e por outro lado o novo público poderá não só apreender esta técnica como inová-la. Valorização, tradição e cultura são algumas das bases para que esta ferramenta versátil seja um catalizador para novas experiências cerâmicas.»
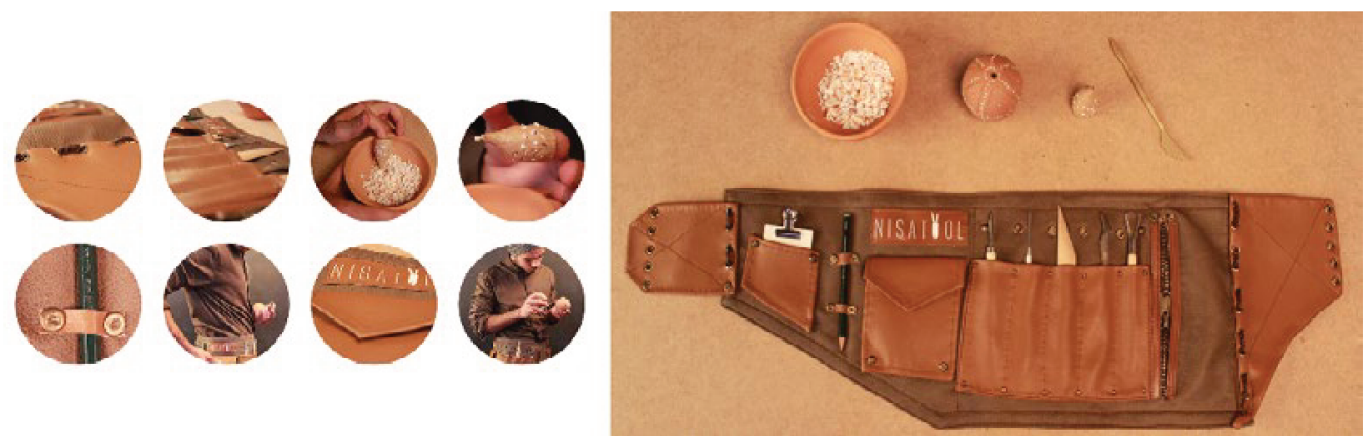

Fig.9 - Pormenores do projeto "Nisatool". Fotos dos autores.

\section{Projeto "Sal" das alunas Andreia Sousa e Leonor Dias}

«O ponto de partida para este trabalho foi uma lancheira, desde esse momento foram desenvolvidos vários desenhos, nomeadamente com a temática das "Memórias", "Produto", "Ergonomia", "Mercado", "Mutações" e "Recombinações", os quais foram a base do projeto. A partir desses desenhos foram surgindo várias ideias e foi desenvolvida uma lancheira apenas para refeições frias, combi- 
nando a olaria de Nisa e um revestimento em cortiça. Ambos os materiais têm características distintas, daí terem sido usadas em simultâneo, complementando-se. Foi usada a olaria, por ter como principal característica a frescura que permanece no interior de cada peça e a cortiça como revestimento para filtrar o calor e para atenuar o impacto do barro em caso de queda. O público alvo adequado a este produto será alguém que acima de tudo goste de andar ao ar livre, fazer piqueniques e ir à praia.»
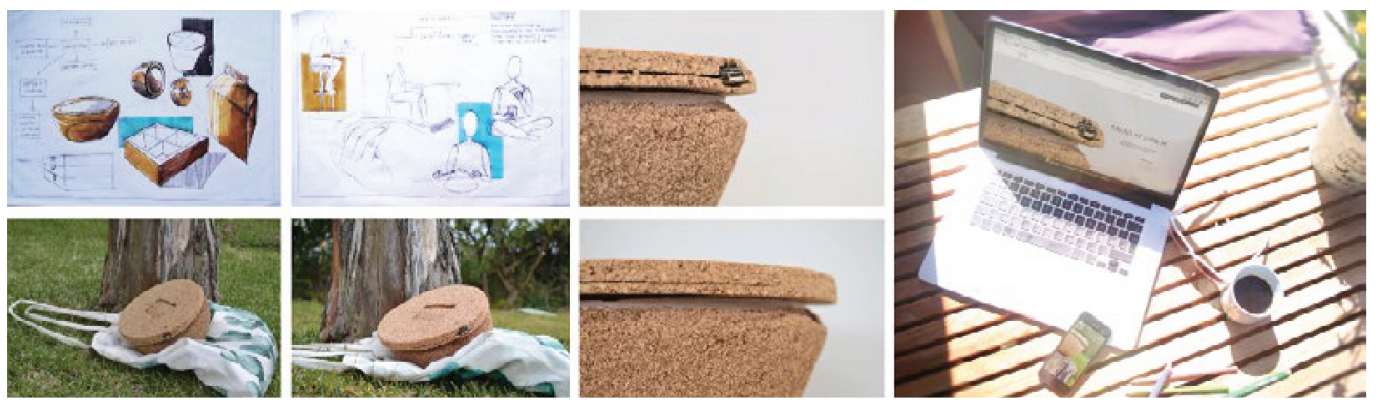

Fig.10 - Sckeching e maqueta da peça "Sal" e mockup do site de divulgação. Foto das autoras.

\section{Projeto "Clayss" dos alunos Andreia Maurício e Bruno Andrade}

«Este projeto consiste em recuperar a identidade de Nisa e Coruche, valorizando a tradição e os produtos que estas terras nos dão. Desenvolveu-se um projeto cujo o objetivo era criar um recipiente que agrupasse todas as características para armazenar alimentos, juntando duas matérias primas distintas: o barro e cortiça. Criou-se neste caso uma garrafa para duas pessoas - permitindo uma melhor arrumação e o fácil transporte - complementada por um conjunto de dois copos que encaixam mutuamente.» 


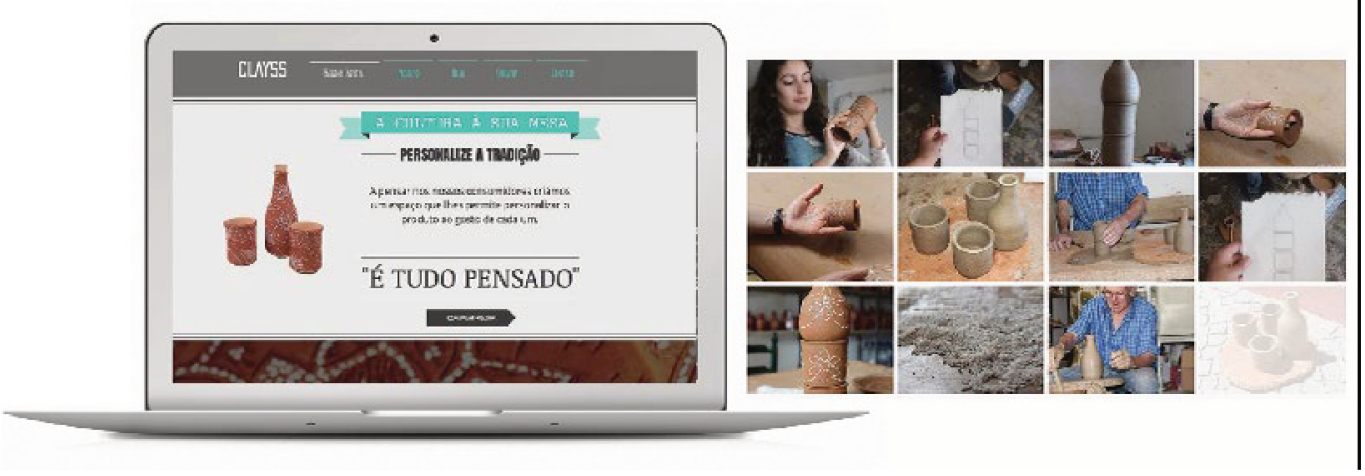

Fig.11 - Mockup do site de divulgação da "Clayss" e conjunto de imagens que retratam a evolução do projeto. Foto dos autores.

\section{Projeto "Eat N'Go" dos alunos Afonso Sousa e Filipa Coelho}

«O nosso conceito parte da ideia de comunidade e de momentos de partilha que pretendemos criar em torno do momento de almoço saudável em ambiente citadino.

Assim definido o produto, portabilidade e interação são características de foco. A ideia de organização e de esquematização constituem a principal influência gráfica: quer da forma da lancheira, quer do site principal.

As peças são produzidas no meio local artesanalmente, de forma a dinamizar a vila de Nisa e dar visibilidade à Olaria Pedrada. Tirando partido do modo de produção, o cliente tem a opção de escolher a cor do vidrado para o interior da peça. O nosso produto é produzido em barro original de Nisa, por forma a fazer-se uso das suas características naturais de arrefecimento. Nas tampas é usado um vedante em Ruber Cork, por forma a garantir o isolamento necessário. $\mathrm{O}$ corpo de revestimento das peças é feito em cortiça, para manter a temperatura e atenuar os ligeiros impactos do dia-a-dia.» 


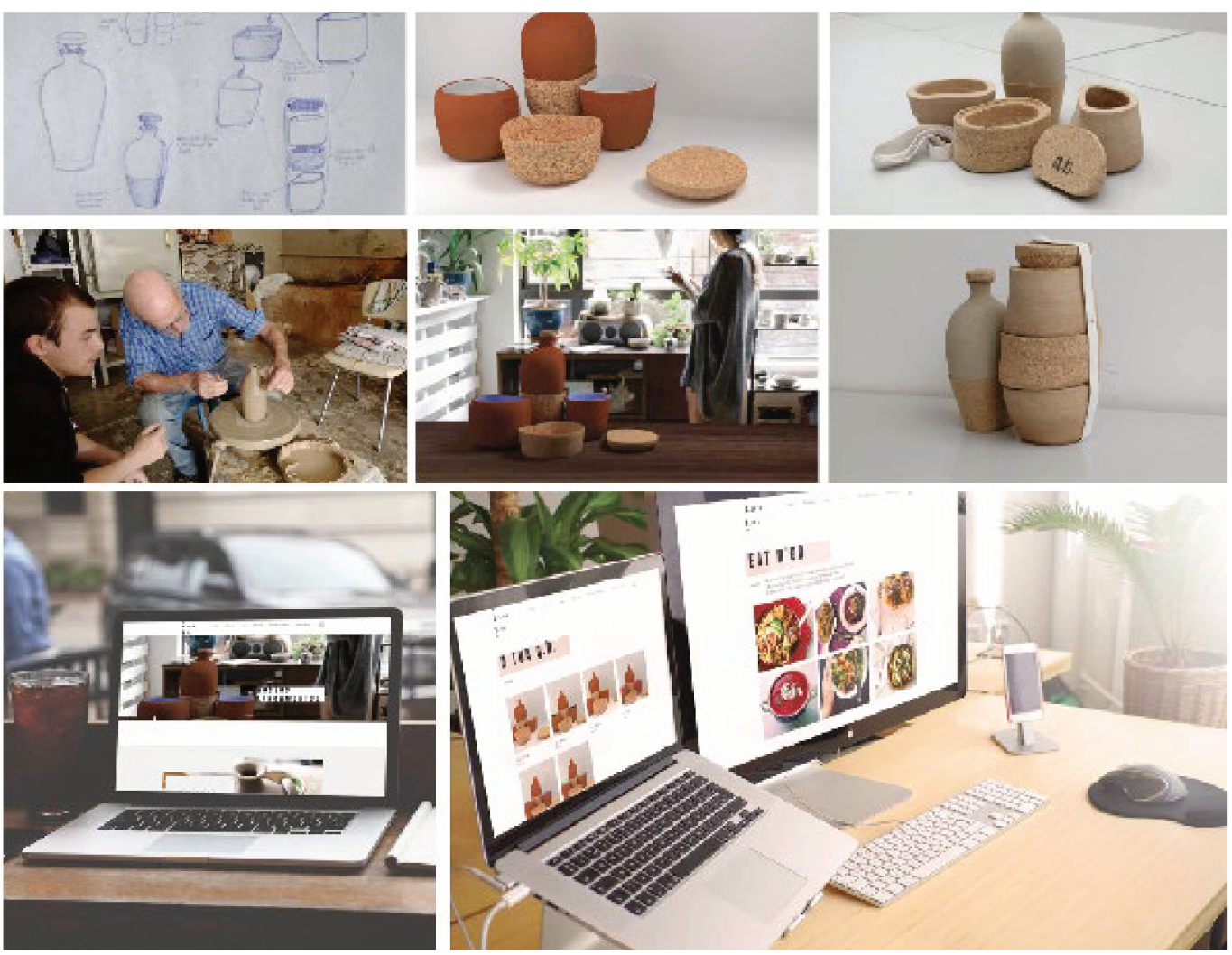

Fig.12 - Conjunto de imagens que retratam a evolução do projeto "Eat N'Go" com o respetivo mockup do site de divulgação. Foto dos autores.

\section{Conclusão}

Por via da nossa ação, juntámos os mais diversos agentes num projeto de responsabilidade e sustentabilidade social. Pela partilha de experiências e questões interdisciplinares em torno do design focado nas causas sociais, empreendeu-se reflexão na gestão participativa de recursos (Guimarães,2013) por parte dos agentes em presença os quais empreenderam o design de novos materiais, novos usos para práticas consagradas pelo tempo, novos produtos ou a sua alternativa desmaterialização em serviços, experiências e observação de efeitos e consequências.

Observando os resultados alcançados pelos dois grupos de foco conclui-se que a diversidade local e a interação de professores e estudantes em plataformas colaborativas científica, cultural e geracionalmente plurais, assumiu um papel muito significativo do ponto de vista metodológico: quer ampliando a capacidade dos agentes para a observação de hipotéticas realidades futuras; quer proporcionando oportunidade para o reenquadrar de assuntos teóricos, por confrontá--los com inputs reais a sua consequente consideração sob vários níveis de complexidade (racional, emocional, cultural, técnico e tecnológicos). Sublinha-se deste processo a exponenciação da aptidão especulativa para além 
do pensamento estritamente lógico e analítico, alargando as vias para o desenvolvimento de novos rumos de ação (inovação).

As considerações sobre a mundividência e os recursos investigativos decorrentes de diversos ramos do design, arte visuais e os atores locais, permitiu-nos, a cada momento, conjunturalmente reenquadrar os problemas emergentes; observá-los sob perspectivas distintas ponderar e considerar os seus diversos níveis de complexidade. Por esta via, concebido na observação, experiência e em resposta às necessidades e às aspirações de um pequeno grupo humano, ultrapassando a observação do homem comum, o projeto foi humanizado. Neste processo, por via imersiva, foi encorajado o produto material e imaterial desenvolvido não para, mas com a comunidade. Desta forma - descentrando o processos de design do designer - volvemo-lo mais capaz de enfoque no utilizador e no contexto de produção e uso, criando valor acrescentado para o projeto.

\footnotetext{
"O processo do design termina quando as equipas já tenham tomado todas as decisões necessárias para definir o produto. Essa definição abarca todos os objectivos (mesmo as escolhas iniciais) e respeita todos os constrangimentos técnicos. Essa definição deve ser documentada por forma a que a equipa de produção consiga implementar o produto. Por isso design é medido em duas dimensões diferentes: através da qualidade e potencial para avançar com o projeto em diante." (Brown, 2013) ${ }^{4}$
}

Em busca de alternativas aos modelos educativos focados na sala de aula, a par de investigação sobre práticas pedagógicas e de investigação em design, estimulou-se mediação, interação e responsabilidade cultural e social. Simultaneamente, logrou-se ampliar o campo perceptual dos vários participantes; os níveis de leitura das realidades material e imaterial em presença; da memória individual e coletiva; de conhecimento científico; de técnicas e tecnologias, contribuído igualmente para a consideração de diversos níveis de significado, como providenciando e propelindo o desenvolvimento de nova ação.

Materializando os resultados obtidos logrou-se a criação, no curto prazo, de uma base de dados open source, a nutrir com a informação coligida no supracitado, como em futuros contextos de investigação aplicada.

De acordo com a Declaração Universal sobre a Diversidade Cultural da UNESCO (2002): a diversidade cultural é factor preponderante no alcançar do bem-

4 "The design process ends when the team has made sufficient decisions to define the product. That definition addresses all the established goals (decisions early in the project) and respects all the technical constraints (perhaps later in the project). 
-estar intelectual, emocional, moral e espiritual da humanidade, constituindo ainda um dos elementos essenciais na transformação das realidades urbanas e sociais. Sendo a diversidade cultural herança comum da humanidade, deve pois reconhecer-se nas suas mais diversas formas a cultura e o conhecimento, preservando-os para benefício da presente e das gerações vindouras.

Para tal, deve o designar observar e tomar em consideração as mais diversas faces da cultura e do conhecimento, por forma a conseguir alcançar quer representações, quer soluções identitariamente satisfatórias. Da observação do processo por nós analisado concluímos ser o desenhar com, a forma mais profícua de observar os diferentes atributos do contexto a servir, reforçando a sua identidade e idealizando da melhor forma os efeitos do projeto.

\section{Referências Bibliográficas}

BROWN, D. Designing Together: The collaboration and conflict management handbook for creative professionals. s.l.: New Riders, 2013.

BÜCHLER, D. \& BIGGS, M. Architectural Design and the problem of Practice-Based Research. Cadernos de Pós-Graduação em Arquitetura e Urbanismo. FAU Mackenzie: s.l., p.1-16,2008.

CANDY, L. Practice Based Research: A Guide. Sydney: University of Technology, 2006.

FERRARA, L. In GASPARETTO, F. vo. EconomyUp It. Agosto, 2016. Disponível em http://www.economyup.it/blog/4620_il-design-e-morto-viva-il-design-collaborativo.htm. Acesso em 9/8/2016.

FUKUDA, S. Age of Subjective Engineering, Emotional Engineering. New York: Springer, 2015.

GUIMARÃES, L. B. de M. A Ideia de Cadeias Produtivas para Implantação de Comunidades Sustentáveis. IX Congresso Nacional de Excelênia em Gestão, Rio de Janeiro: CNEG, p.1-22,2013.

HALL, S., A identidade cultural na pós-modernidade. Rio de Janeiro: DP\&A Editora, [1992] 2004. 
JUEZ, F. M. Contribuciones para una antropología del diseño. Barcelona: Gedisa, 2002.

MAYR, E. \& Provine, W. The Evolutionary Synthesis: Perspectives on the Unification of Biology. 4a ed. Harvard: Harvard Univerity Press, [1980]1998.

RIJO, C. Design de comunicação cultura, identidade dos sítios e suas representações. Alcântara, do sítio aos sítios: território para um modelo. 2015. Tese (Doutoramento em Design) - Faculdade de Arquitectura, Lisboa.

RIJO, C. A Identidade dos espaços e o design: uma questão de responsabilidade

social", Revista I.E. Maio de 2014.

RIJO, C. Identity: From Global to Local. In: MERLY S. (ed.) Cultural Diversity International Perspectives, Impacts on the Workplace and Educational Challenges. Nova Science Publisher, Inc.: New York, 2014, p. 140-159. ISBN: 978-163321-696-9. 
Cátia Rijo é Doutorada em Design (desde 2015) pela Faculdade de Arquitetura de Lisboa, Mestre em Produção gráfica (2008) e Licenciada em Design Visual (2000) ambos pelo IADE (Instituto de Artes visuais, design e Marketing).

Atualmente é professora Adjunta na Escola Superior de Educação de Lisboa, no Instituto Politécnico de Lisboa, onde lecciona as disciplinas relacionadas com Design (design gráfico, design de interação, Metodologias de Design, Teoria e História do Design, entre outras.) Anteriormente, de 2008 a 2013, foi Professora Assistente no IADE onde lecionou disciplinas relacionadas com Design.

É membro investigadora no CIAUD (desde 2008) e no Centro Interdisciplinar de Estudos Educacionais da Escola Superior de Educação de Lisboa (desde 2015). No curso de Artes Visuais e Tecnologias (ESELx) desenvolve pesquisa, com colegas de trabalho, sobre metodologias de ensino e pesquisa em design.

Publica regularmente artigos, nacionais e internacionais, em revistas da especialidade e participa frequentemente em congressos internacionais e nacionais. É membro de comissão científica em diversos jornais e conferências e é regulamente convidada a integrar júris de Mestrados e doutoramentos.

Helena Grácio é licenciada desde 2001 pela Universidade Lusíada de Lisboa. Começou sua carreira profissional um designer em gráfica e em design de produto. Em 2005 fez uma especialização em joalharia contemporânea na Faculdade de Belas Artes de Lisboa, que levou a um projeto em objetos de adorno com matérias primas tradicionais portuguesas.

Em 2007 foi co-fundadora da Oficina do Desenho, uma associação cultural sem fins lucrativos cultural, onde lecionou na área de desenho e ilustração. Em 2009, inicia o Doutoramento em design na Faculdade de Arquitetura da Universidade de Lisboa, com o tema; "Quartz Embutidos Olaria de Nisa: de Design de artesanato de produto". Em 2010 esteve na coordenação da Licenciatura em Design Social do IPA.

No âmbito do seu doutoramento, fundou em 2013 Crafts2Design - Associação para

a Proteção do Património Cultural, que visa promover e salvaguardar o património cultural, através da interação da prática do design com artesanato.

Atualmente é professora Adjunta na Escola Superior de Educação, Politécnico de Lisboa na área do design de produto e empreendorismo.

É membro investigadora no CIAUD (desde 2009) e no curso de Artes Visuais e Tecnologias (ESELX) desenvolve pesquisa, com colegas de trabalho, sobre metodologias de ensino e pesquisa em design. 
Sandra Antunes é professora de Design de Produto no curso de Licenciatura em Artes Visuais e Tecnologias da Escola Superior de Educação do Instituto Politécnico de Lisboa (ESELx). É doutoranda em Design/História da Cultura Material e Imaterial e pós-graduada em Design de Produto pelo Instituto de Arte, Design e Empresa - Universitário de Lisboa (IADE-U). É ainda pós-graduada em Pedagogia pela Faculdade de Psicologia e Ciências da Educação da Universidade de Lisboa; Mestre em Teorias da Arte e Licenciada em Artes Plásticas-Pintura, pela Faculdade de Belas-Artes da Universidade de Lisboa.

Atualmente Sandra integra o grupo de investigação "Mapear Design - História, Produtos, Cultura e Identidade" (IADE-U) e o Centro Interdisciplinar de Estudos Educacionais da Escola Superior de Educação de Lisboa.

No círculo científico das Teorias da Arte, Sandra possui investigação publicada a respeito do Desenho e da concepção sobre o corpo tecida no âmbito do pensamento ontológico da Contra-Reforma na Península Ibérica. Desde 1998 vem desenvolvendo investigação prática aplicada às Artes Plásticas (Desenho, Pintura e Escultura). No curso de Artes Visuais e Tecnologias (ESELX) desenvolve pesquisa, com colegas de trabalho, sobre metodologias de ensino e pesquisa em design.

Recebido em: 15/08/2016

Aceito em: 21/10/2016 